\title{
A ENCICLOPÉDIA COMO FONTE PARA A HISTÓRIA DA INDÚSTRIA NO SÉCULO XVIII
}

1. O modelo enciclopédico, em virtude das marcas conjunturais de que não pode fugir, tem variado ao longo do tempo. Com efeito, às «constantes» — de pressupostos e funções — sobrepõem-se as «transformações» de tal modo que a «nova geração» das enciclopédias apresenta características deveras inovadoras, em relação às suas congéneres da Idade Média ( $\left.{ }^{2}\right)$ ou mesmo da Idade Moderna Que separa, pois, as enciclopédias da «velha» e da «nova» geração?

Poder-se-ia dizer, de forma sintética, que as separa a distância que vai do conhecimento, pressupostamente exaustivo e correlacionado, à compreensão de determinadas temáticas e aos diversos graus de problematização por elas suscitados. Assim, para os enciclopedistas de meados de Setecentos, «le but d'une Encyclopédie est de rassembler connoissances éparses sur la surface de la terre; d'en exposer le système général aux hommes avec nous vivons, et de le transmettre aux hommes qui viendront après nous» $\left({ }^{4}\right)$. Para Lucien Febvre — que pode ser considerado um dos primeiros corifeus das enciclopédias da nova geração - a tónica já é colocada na compreensão, como se verifica pela seguinte passagem da Encyclopédie Française: «Compiler tout, exposer tout,

(1) Alfredo Salsano, «Postcriptum, 1984», Prelo, n. ${ }^{\circ}$ 4, 1984, pp. 36-37.

${ }^{2}$ ) Ver José Mattoso, «As enciclopédias medievais», Prelo, n. ${ }^{\circ} 4$, 1984, pp. 43-51.

$\left({ }^{3}\right)$ Ver Alfredo Salsano, «O modelo enciclopédico e as suas variações» e «Postcriptum, 1984», Prelo, n. ${ }^{\circ}$ 4, 1984, pp. 9-33 e 34-41.

(4) M. Diderot e M. d'Alembert (dir.), Encyclopédie, ou Dictionnaire raisonné des sciences, des arts et des métiers, par une société de gens de lettres, t. v, Paris, Briasson, David, Le Bruton, Durand, 1755, p. 635. 
prendre tout, prendre pour devise : Faire connaitre?». Non. «Faire comprendre» $\left({ }^{5}\right)$.

Apenas acrescentaria que esta nova concepção de enciclopédia, embora desenvolvida e consolidada essencialmente no século $\mathrm{x}$, já se encontrava em gestação desde os finais do século XVIII. Com efeito, existe um prenúncio da referida concepção na Encyclopédie Méthodique $\left(^{6}\right)$ que continuou e, em parte, superou a própria Encyclopédie de Diderot et d'Alembert $\left({ }^{7}\right)$.

2. A Encyclopédie, ou Dictionnaire raisonné des sciences, des arts et des métiers - de que, em especial, aqui me ocupo tem sido objecto de interpretações díspares, quanto às respectivas informações sobre a história da indústria, da tecnologia e do próprio desenvolvimento industrial. Analisemos apenas dois exemplos das ditas interpretações, elucidativos por se encontrarem nos antí podas um do outro.

Para M. Gérard Vassails, «l'Encyclopédie est le premier et monumental ouvrage de technologie moderne générale (la technologie étant l'application de la science à l'industrie). L'Encyclo pédie a une tendance générale à la promotion du machinisme, à la science investie dans la production» $\left(^{8}\right)$. Por seu lado, para Roland «l'Encyclopédie avait un caractère retardataire, ne

(') Lucien Febvre, «Une Encyclopédie Française: Pourquoi, comment?», Lucien Febvre (dir.), Encyclopédie Française, t. I, Paris, Société de Gestion de I'Encyclopédie Française-Editeur, 1937, p. 1.04.14.

$\left(^{\circ}\right)$ Encyclopédie méthodique, ou par ordre des matières, Paris, Panckoucke, 1785 e anos seguintes.

(') Note-se, contudo, que poucos anos após o inicio da publicação da Encyclopédie méthodique, ela era considerada a 3." ed. da Encyclopédie, dir. por Diderot e d'Alembert (cfr. L'esprit de l'Encyclopédie ou choix des articles les plus agréables, les plus piquans de ce grand Dictionnaire, t. I, Paris, Fauvelle et Sagner, 1798, p. v). Ver outros elementos sobre enciclopédias em: M. Antunes, «Enciclopédia»e M. Alves de Oliveira, «Principais enciclopédias do mundo ocidental», Verbo - Enciclopédia Luso-Brasileira de Cultura, vol. $7^{\circ}$, Lisboa, Ed. Verbo, 1968, cols. 495-500.

$\left.{ }^{8}\right)$ M. Gérard Vassails, «L'Encyclopédie et la physique», Revue d'Histoire des Sciences, t. IV, 1951 (pp. 294-323), apud Roland Mousnier, Progrès scientifique et technique au XVIII siècle, Paris, Librairie Plon, 1958, p. 223. 
pouvait pas ouvrir la voie à la recherche, et ne répondait pas à ce que l'on pouvait attendre d'un semblable dictionnaire» $\left({ }^{9}\right)$.

Trata-se de duas posições extremas, demasiado genéricas e, consequentemente, um tanto simplificadoras. Dado o âmbito e a extensão da Encyclopédie - 35 volumes, logo na 1. edição, publicados entre 1751 e 1780 - torna-se imprescindível distinguir, do ponto de vista da história da indústria e da tecnologia, os seguintes parâmetros: artigos/temas; fontes utilizadas pelos respectivos autores dos artigos; data de elaboração e/ou de publicação dos textos; autores e respectiva preparação.

Há, todavia, um aspecto que, segundo julgo, não suscita grande controvérsia e que se refere ao prestimoso contributo da Enciclopédia para que a manufactura/indústria viesse a conquistar uma certa dignidade que até então - e, por vezes, mesmo posteriormente- lhe fora negada. Sob esta perspectiva, bem se pode afirmar que a monumental obra de Diderot, d'Alembert e colaboradores constitui um elemento de peso, para o lançamento de uma cultura científico-técnica que, quer se deseje ou não, é aquela que tem impregnado os últimos dois séculos. Com efeito, a diversos outros artigos se aplica o que já foi afirmado especificamente quanto aos de Diderot: «Tout article de Diderot, quel que soit son contenu, a d'abord pour but de modifier l'opinion du lecteur pour en faire un citoyen plus éclairé, plus utile, et faire avancer par là une révolution nécessaire» $\left({ }^{10}\right)$.

Apesar de já anteriormente os autores mercantilistas terem chamado a atenção para o papel da indústria - cujo desenvolvimento, numa perspectiva macroeconómica, permitiria reduzir as importações e, consequentemente, a saída de dinheiro —, conti nuava a ser necessário, por meados de Setecentos, reafirmar a importância daquela actividade. Os directores/editores da Encyclopédie aproveitaram o ensejo para focar as «artes mecânicas», não só ao abordarem as «artes liberais» como no artigo «arte».

Era enorme o desconhecimento em tal matéria, pelo que Diderot e d'Alembert tinham consciência nítida de que apenas procuravam dar um primeiro passo, mas que essa ingente tarefa

(') Roland Mousnier, idem, p. 228.

$\left({ }^{10}\right)$ Jacques Proust, Diderot et VEncyclopédie, Paris, A. Colin, 1962, p. 6 . 
teria que ser continuada no futuro. A propósito, pode ler-se, no «Advertissement des Editeurs», do tomo ra: «Enfin dans la partie des Arts, si étendue, si délicate, si importante, et si peu connue, l'Encyclopédie commencera ce que les générations suivantes finiront ou perfectionneront [...]. Les Arts, ces monuments précieux de l'industrie humaine, n'auront plus à craindre de se perdre dans l'oubli; les faits ne seront plus ensevelis dans les atteliers et dans les mains des Artistes» $\left({ }^{11}\right)$.

Quanto à distinção entre «artes liberais»e «artes mecânicas», ela é não só admitida como justificada historicamente $\left(^{12}\right)$. Contudo, já a superioridade das primeiras, geralmente admitida, é considerada injusta e muito prejudicial, como se comprova pela seguinte passagem: «Le mépris qu'on a pour les Arts méchaniques semble avoir influé jusqu'à un certain point sur les inventeurs mêmes. Les noms de ces bienfaiteurs du genre humain sont presque tous inconnus, tandis que l'histoire de ses destructeurs, c'est-à-dire, des conquérans, n'est ignorée de personne». E acres $\neg$ centa-se: «Cependant c'est peut-être chez les Artisans qu'il faut aller chercher les preuves les plus admirables de la sagacité de l'esprit, de sa patience et de ses ressources» $\left({ }^{13}\right)$.

Como é sabido, foi enorme o êxito editorial da Enciclopédia. Dai que as ideias nela expressas, em prol das artes mecânicas — ilustradas com excelentes gravuras, nos 11 volumes de «Tables» — tenham tido uma difusão excepcional Também acerca deste

(11) M. Diderot e M. d'Alembert (dir.), Encyclopédie, ou Dictionnaire raisonné..., t. III, 1753, p. v.

$\left.{ }^{(12}\right)$ «En examinant les productions des arts, on s'est apperçû que les unes étoient plus l'ouvrage de l'esprit que de la main, et qu'au contraire d'autres etoient plus l'ouvrage de la main que de l'esprit. Telle est en partie l'origine de la prééminence que l'on a accordée à certains arts sur d'autres, et de la distribution qu'on a faite des arts en arts libéraux et en arts mécaniques» (M. Diderot e d'Alembert (dir.), Encyclopédie, ou Dictionnaire raisonné t. I, 1751, p. 714).

$\left({ }^{13}\right)$ M. Diderot e d'Alembert, idem, t. I, p. XIII. Cfr também o artigo «Arte», t. I, pp. 713-717. Algumas passagens, relativas a esta temática, encontram-se transcritas em: Encyclopédie (Extraits),avec une notice biographique, une notice historique et littéraire, des notes explicatives, des judgements, un questionnaire et des sugets de devoirs, par Jean Voilquin, Paris, Librairie Larousse, s. d., pp. 47-50 («Les Arts mécaniques»).

$\left({ }^{14}\right) \quad$ Ver J. Proust, Diderot et l'Encyclopédie, cap. II, pp. 45-79 («Histoire de la manufacture Encyclopédie»). 
A enciclopédia como fonte para a hist. da indús. no séc. XVIII 85

aspecto particular, a obra em análise terá cumprido a sua dupla função: destrutiva (no que se refere a uma mentalidade tradicional elitista) e construtiva (no sentido de dignificar actividades até aí encaradas como de segunda ordem

Mas não nos iludamos. O que os enciclopedistas do século XVI conseguiram - e já não foi pouco! - foi dar início a um longo processo, que continuou até aos nossos dias, e que consiste em chamar a atenção para a história da actividade do homem, na sua vertente de transformador de matérias-primas (de forma artesanal ou industrial). À iniciativa e ao esforço daqueles, muitos historiadores têm dado sequência, em particular já no nosso século. Entre muitos outros, recordem-se os nomes de: Paul Mantoux e Lucien Febvre; Pierre Léon, Bertrand Gille e Jordi Nadal; Michel Daumas, Kenneth Hudson e Marc-A. Barblan.

3. A Encyclopédie foi publicada num período de transição, entre a indústria característica do antigo regime - artesanal c manufactureira-e a grande indústria - mecanizada e de produção em série -, resultante da revolução industrial ou, se se preferir, da industrialização. $\grave{A}$ realidade, que em diversos aspectos se encontrava em mutação, correspondia o uso de determinados conceitos, cuja análise convirá prosseguir, na sequência de importantes estudos já publicados $\left({ }^{16}\right)$.

Conhecemos já a evolução da palavra «indústria», em França e em Portugal, graças às pesquisas de, respectivamente, Paul

$\left({ }^{15}\right)$ Alfredo Salsano, «O modelo enciclopédico e as suas variações», Prelo, n. ${ }^{\circ}$ 4, 1984, p. 22.

$\left({ }^{16}\right)$ Entre outros, atente-se nos seguintes trabalhos, respectivamente sobre a França c sobre Portugal: Paul Harsin, «De quand date le mot industrie ?», Annales d'Histoire Economique et Sociale, t. II, 1930, pp. 235-242; Bernard Quemada, «Technique et langage - La formation des vocabulaires français des techniques», Bertrand Gille (dir.), Histoire des Techniques Techniques et civilisations. Techniques et sciences, «Encyclopédie do I | Pléiade», Paris, Gallimard, 1978, pp. 1146-1240; Joel Serrão, «A indústria -A palavra e a ideia», Temas oitocentistas. Para a história de Portugal no século passado, vol. I, 2 ed., Lisboa, Livros Horizonte, 1980, p p. 96-99. No que se reporta a Coimbra, fizemos uma ligeira referência ao assunto um obra intitulada $A$ área económica de Coimbra. Estrutura e desenvolvimento industrial, 1867-1927, Coimbra, Comissão de Coordenação da Região Contro, 1984, p. 19. 
Harsin e Joel Serrão. Também Bernard Quemada, no capítulo «Technique et langage», da obra Histoire des techniques, fornece elementos importantes $\left({ }^{17}\right)$. Contudo, a investigação deveria ser alargada, a dois níveis:

-a outros conceitos e/ou expressões ;

-a outros países e/ou áreas.

Nessa pesquisa, a Enciclopédia - abrangendo não só a 1. edição e respectivos suplementos, mas também as seguintes, incluindo a própria Enciclopédia Metódica $\left({ }^{18}\right)$ - poderá ocupar, comofonte, um lugar proeminente, pela profusão dos artigos e das gravuras que apresenta e pelas alterações que se foram verificando e que ficaram registadas na mencionada obra.

Em artigo não assinado - muito provavelmente de Diderot $\left({ }^{19}\right)$ - , dá-se conta da imprecisão da linguagem das artes — no sentido de «artes mecânicas» ou «indústrias» - , bem como do aparecimento de novos vocábulos, o que denota, em parte, a existência de alterações, inerentes a qualquer período de transição. Acerca da linguagem das artes, afirma-se: «J'ai trouvé la langue des Arts très-imparfaite par deux causes; la disette des mots propres, et l'abondance de synonymes. Il y a des outils qui ont plusieurs noms différens; d'autres n'ont au contraire que le nom générique, engin, machine, sans aucune addition qui les spécifie : quelquefois la moindre petite différence suffit aux Artistes pour

$\left({ }^{17}\right)$ Cfr. nota 16. Por alturas da publicação da Encyclopédie, o vocábulo «indústria» ainda não havia adquirido o seu significado moderno, pois era usado como sinónimo de «fábrica» ou de «manufactura» (Cfr. Albert Soboul, La Révolution Française, vol. 1 : De la Bastille à la Gironde, Paris, Édtions Sociales, p. 44, 1962).

$\left({ }^{18}\right)$ O que é sublinhado por J. Proust noutro contexto - os enciclopedistas face à Revolução-também se aplica à temática em foco: «[...] mais il est évident que l'enquête complète devra aussi porter sur ceux qui ont participé aux suppléments, à VEncyclopédieméthodique, et d'une façon générale sur tous qui ont partagé peau ou prou l'idéal encyclopédique, comme Malesherbes, Condorcet, ou l'abbé Raynal» (Jacques Proust, Diderot et $V$ Encyclopédie,p. 42 ).

$\left(^{19}\right)$ Sobre a atribuição de artigos não assinados a Diderot-com algumas reservas, sobretudo a partir do tomo u - ver J. Proust, idem, pp. 131-149. 
A enciclopédia como fonte para a hist. da indús. no séc. XVIII 87

abandonner le nom générique et inventer noms particuliers; d'autres fois, un outil singulier par la forme et son usage, ou n'a point de nom, ou porte le nom d'un autre outil avec lequel il n'a rien de commun [..._. La langue change en grande partie d'une manufacture à une autre» $\left({ }^{20}\right)$.

Entre os vocábulos cuja história conviria averiguar, a montante e ajusante do terceiro quartel do século XVIII, podem mencionar-se :

. «artisan». «On dit d'un bon cordonnier», mas que, quando aplicado a relojoeiro («horloger»), é substituído por «artiste» $\left({ }^{21}\right)$.

que podia referir-se a um dos melhores artistas mecânicos ou, se aplicado a um preparador de quimica - como hoje diríamos-, significava o desempenho de uma actividade relativamente subalterna $\left({ }^{22}\right)$.

- «fábrica», usada em 1756 (t. VI da Encyclopédie, p. 351) em sentido tradicional-maneira de construir, edifício considerável, construção de qualidade —, já em 1783 (Encyclopédie méthodique - Recueil de Planches, t. I. Pls. 1 a 5) é utilizada numa acepção moderna, industrial, como em «fabrique des armes». Embora se tratasse mais propriamente de uma manufactura, é evidente a evolução no significado do termo «fábrica», em menos de três décadas (1756-1783).

. «manufacture» (Encyclopédie -, t. x, 1765, pp. 60-62), no conhecido artigo onde se faz a distinção entre manufacturas reunidas (ou concentradas) e manufacturas dispersas $\left({ }^{23}\right)$. A investigação deste assunto poderá adquirir novos contornos, devido aos recentes contributos da his

$\left(^{20}\right)$ «Art», M. Diderot e M. d'Alembert (dir.), Encyclopédie, ou Ou tionnaire raisonné..., t. I, 1751, p. 716.

$\left({ }^{21}\right)$ «Artisan», M. Diderot e M. d'Alembert (dir), idem, t. I, p. 745,

$\left({ }^{22}\right)$ «Artiste», M. Diderot et d'Alembert (dir.), idem, t. I, p. 745

$\left({ }^{23}\right)$ A Enciclopédia tem sido considerada como uma fonte clássica sobre o assunto, para a qual remete, por exempta, A. Soboul, ao focar a «industrie rurale» e a «manufacture réunie» (Albert Soboul, La France à la veille de la Révolution. Economie et société, 2." ed., rev. e aumentada Paris, Société d'Edition d'Enseignement Supérieur, 1974, pp. 32-35). 
toriografia sobre a indústria ao domicílio e, particularmente, sobre a proto-industrialização.

- «máquina», aplicada a mecanismos relativamente simples (Encyclopédie méthodique Recueil de Planches, t. VIII, 1790, Pls. 1 a 3 - «Machine à faire peignes») ou à própria máquina atmosférica, antecessora da máquina a vapor («Feu, Pompe à Encyclopédie _,t. VI, 1756, pp. 603-612).

Em suma: os editores/directores e os colaboradores da Enciclopédia não desprezaram a conceptualização nem tão-pouco as designações técnicas.

4. Para concluir, gostaria ainda de focar a Enciclopédia e a Revolução Industrial.

$\mathrm{Na}$ sequência do já referido anteriormente, não é possível dar uma resposta simples à temática das relações entre os dois fenómenos em epígrafe.

Pelo menos nos primeiros volumes da Enciclopédia, publicados nos anos 50 do século XVIII, dir-se-ia que a dita obra fornece informações de uma indústria típica do antigo regime. Contudo, mesmo neste caso, há referências que não são despiciendas para a análise da industrialização que se avizinhava:

-qualidade e abundância das matérias-primas em determinadas áreas;

-superioridade de alguns ramos da indústria em certas zonas ou países. É o caso da indústria da seda, em certas regiões francesas-como na de Lyon - e no Piemonte $\left({ }^{24}\right)$; -experiências e ensaios com novos maquinismos.

Dessa informação, uma reporta-se à realidade dos fins do século XVII ou dos princípios do século XVIII ou, pelo menos, a uma realidade que prevalecia, em meados do século, sem grande altera ção. Outro tipo de informação era obtido dos próprios artesãos/ /operários, em alguns casos através de visitas às oficinas. Sim plesmente, se a informação assim obtida é importante, escasseiam as referências exactas às fontes. Apenas um número reduzido de

$\left({ }^{24}\right)$ «Soie», M. Diderot e d'Alembert (dir.), idem, t. xv, 1765, pp. 269 e 271-284. 
«artistas» é mencionado, como que na sequência-e, em certa medida, como resultado - do esquecimento a que, até aí, haviam estado votados. Ao facto alude Jacques Proust, quer na sua excelente obra, intitulada Diderot et l'Encyclopédie $\left({ }^{25}\right)$, quer no artigo sobre «La documentation technique de Diderot dans Y Encyclopédie», publicado na Revue d'Histoire Littéraire de la France, em $1957\left(\left(^{26}\right)\right.$.

Penso, no entanto, que há que prosseguir as investigações, se possível nos arquivos empresariais que, eventualmente, ainda existam, a fim de completar ou colmatar algumas lacunas, sobre as fontes utilizadas pelos enciclopedistas, relativamente à indústria e à tecnologia.

Com a actualização da Encyclopédie, a partir da 3. a edição (Encyclopédie méthodique e respectivas Planches, após 1782), começava a ser possível fornecer alguns elementos sobre a revolução industrial, já em curso na Grã-Bretanha. Mas, também aqui, há que prosseguir a investigação, com o intuito de esclarecer mais aprofundadamente :

- quais os principais canais de informação utilizados: técnicos, operários, empresários, publicações, espiões industriais ou outros?

- que impacto tiveram essas informações nos leitores da Enciclopédia?

Outras questões, embora de carácter mais geral mas relacio $\neg$ nadas com estas, se podem formular.

Segundo já foi admitido, da emulação entre os editores da

$\left({ }^{25}\right)$ Paris, A. Colin, 1962, pp. 23-24.

$\left({ }^{26}\right) 57 .^{\circ}$ ano, $n .^{\circ}$ 3, 1957, pp. 334-352. No artigo citado, podo ler-se : «Quelque fois la source n'est pas nommée, ou ne l'est que d'une façon imprécise, mais le contenu du texte utilisé est assez caractéristique pour qu'on puisse retrouver l'ouvrage. Le plus souvent aucune source n'est indiquiée aucun rapprochement ne s'impose, et nous devons nous résigner à l’igno rance, au moins jusqu'à ce qu'un heureux hasard vienne nous éclairers (Jacques Proust, La documentation technique de Diderot dans l'Encyclopédie, p. 334). Os próprios autores da literatura de propaganda, publicada aquando da Revolução Francesa, pouco se preocupavam com as classes trabalhadoras, camponeses ou pequenos artesãos, como sublinha Albert Soboul (La Révolution Française, vol. 1, p. 139). 
Enciclopédia e a Academia das Ciências de Paris terá resultado uma maior divulgação de assuntos de índole industrial e tecnológica. Contudo, o pendor da referida Academia para a ciência pura não terá refreado, um pouco a contra-corrente, a acção da Enciclopédia?

Por outro lado, ao invés do que seria lícito esperar em meados do século XVIII - pelo interesse que procurava dedicar-se à questão industrial -, seria difícil prever que a industrialização em França só se intensificaria já bem entrado o século XIX. Assim, ocorre perguntar:

- qual o papel efectivo que foi desempenhado pela Enciclo pédia?

. que factores negativos terão adiado a descolagem em França, para cerca de meio século após a sua congénere britânica?

Para além dos bloqueios geralmente focados - políticos e sociais -, que peso se poderá atribuir aos seguintes: preparação técnica, de empresários, técnicos propriamente ditos e operários? A que grupos sociais chegariam as obras de carácter geral, como a Enciclopédia, ou mesmo outras de carácter mais especializado?

Em conclusão: a Encyclopédie contém elementos que fazem dela uma fonte de considerável importância para a história da indústria, da tecnologia e mesmo da novel arqueologia industrial. Por esse motivo, impõe-se «revisita-la», utilizando, para o efeito, metodologia e categorias actualizadas, à luz dos resultados da investigação mais recente.

JOSÉ M. AMADO MENDES

Faculdade de Letras

da Universidade de Coimbra 